Research Paper

\title{
Cordycepin attenuates Salivary Hypofunction through the Prevention of Oxidative Stress in Human Submandibular Gland Cells
}

\author{
Atchara Jaiboonma ${ }^{1,2}$, Palakorn Kaokaen ${ }^{1,2}$, Nipha Chaicharoenaudomrung2, Phongsakorn Kunhorm², \\ Kajohnkiart Janebodin ${ }^{3}$, Parinya Noisa², and Paiboon Jitprasertwong ${ }^{1}$ \\ 1. School of Geriatric Oral Health, Institute of Dentistry, Suranaree University of Technology, Nakhon Ratchasima, Thailand \\ 2. Laboratory of Cell-Based Assays and Innovations, School of Biotechnology, Institute of Agricultural Technology, Suranaree University of Technology, \\ Nakhon Ratchasima, Thailand. \\ 3. Department of Anatomy, Faculty of Dentistry, Mahidol University, Bangkok, Thailand. \\ $\triangle$ Corresponding author: Asst. Prof. Paiboon Jitprasertwong, DDS, MSc, PhD, E-mail: paiboonj@sut.ac.th; Tel.: ++66(0)44223582; Fax: ++66(0)44223580.
}

(c) The author(s). This is an open access article distributed under the terms of the Creative Commons Attribution License (https://creativecommons.org/licenses/by/4.0/). See http://ivyspring.com/terms for full terms and conditions.

Received: 2020.04.06; Accepted: 2020.06.26; Published: 2020.07.06

\begin{abstract}
Xerostomia (dry mouth) is a significant age-related condition. Meanwhile, cordycepin, the natural therapeutic agent, has demonstrated an anti-aging effect. Therefore, the present study aimed to investigate the preventive effects of cordycepin on secretory function in an in vitro model of hydrogen peroxide $\left(\mathrm{H}_{2} \mathrm{O}_{2}\right.$ )-induced salivary hypofunction. After being exposed to $\mathrm{H}_{2} \mathrm{O}_{2}$, human submandibular gland (HSG) cells were treated with various concentrations of cordycepin $(6.25-50 \mu \mathrm{M})$ for 24,48 , and $72 \mathrm{~h}$. To evaluate cell proliferation and reactive oxygen species (ROS) generation, 3-(4, 5-dimethylthiazol-2-yl)-2, 5-diphenyltetrazolium bromide and 2, 7'-dichlorodihydrofluorescein diacetate assays were performed. The amylase activity was kinetically measured by 2 -chloro-p-nitrophenol linked with maltotrioside. The expression of salivary, antioxidant and apoptotic markers at mRNA and protein levels were performed by reverse transcriptase polymerase chain reaction (RT-PCR) and immunofluorescence analysis, respectively. We demonstrated that cordycepin (6.25-25 $\mu \mathrm{M})$ contributed to significant increases in expression of the salivary marker genes, alpha-amylase $I$ (AMYIA) and aquaporin-5 (AQP5), and in amylase secretion without changes in cell viability. Under oxidative stress, HSG cells showed remarkable dysfunction. Cordycepin rescued the protective effects partially by decreasing ROS generation and restoring the expression of the salivary proteins, AMY and AQP5 via anti-oxidant and anti-apoptotic activity. In addition, the amount of amylase that was secreted from HSG cells cultured in cordycepin was increased. In conclusion, cordycepin demonstrated a protective effect on $\mathrm{H}_{2} \mathrm{O}_{2}$-induced $\mathrm{HSG}$ cells by decreasing ROS generation and upregulating the salivary function markers, $A M Y I A$ and $A Q P 5$, at both the transcriptional and translational levels.
\end{abstract}

Key words: cordycepin; salivary gland; xerostomia; saliva; dry mouth

\section{Introduction}

Xerostomia, also referred to as dry mouth, is dryness of the oral cavity caused by a low salivary flow rate, lack of saliva and change in the chemical composition of saliva [1,2]. Therefore, salivary gland dysfunction or salivary hypofunction causes dry mouth, which can lead to several clinical conditions, including mastication problems and a decline in the quality of life, especially for patients who have received radiation as part of cancer therapy and elderly persons [3, 4]. Furthermore, salivary hypofunction is defined as an objective reduction in the salivary flow rate involving physiological atrophy of the salivary gland, which manifests itself as morphological alteration in the gland $[5,6]$.

Reactive oxygen species (ROS) are one of main causes of oxidative stress, contributing to cell aging, and are strongly associated with age-related diseases [7]. ROS and other free radicals are usually reduced 
by antioxidants in the body, the so-called oxidation-reduction regulatory mechanism; hence, the accumulation of ROS within the body is repressed [8, 9]. However, antioxidant activity declines with age by interfering with the redox balance, resulting in protein denaturation, DNA damage, lipid peroxidation and apoptosis [10]. Thus, oxidative stress can probably affect the secretory function of salivary glands in the elderly [11]. Nevertheless, the relationship between age-related salivary hypofunction and oxidative stress has not been defined [12].

Cordycepin, also known as 3-deoxyadenosine, is one of the major bioactive compounds of Cordycepes sp., exerting various pharmaceutical properties (e.g. antitumor, anticancer and immunoregulatory effects $[13,14]$. Furthermore, the antioxidant activity of cordycepin has been recently studied [15]. In addition, cordycepin could protect cells against oxidative stress, which induces cell damage. Cordycepin has also been demonstrated to inhibit mitochondrial injury and improve immune responses by scavenging ROS [16, 17]. Previous studies have reported that cordycepin inhibits ROS generation and protects several cells (i.e. neuron and mesenchymal stem cells) from oxidative stress [18-20]. Additionally, cordycepin could have antioxidant activity and attenuate oxidative stress in vivo [15].

However, the preventive effect of cordycepin on the dry mouth experimental model is still unclear. This research aimed to examine the effect of cordycepin on improvements in salivary secretion of $\mathrm{H}_{2} \mathrm{O}_{2}$-induced salivary hypofunction with xerostomia in human submandibular gland (HSG) cells in vitro.

\section{Materials and Methods}

\section{Chemicals and reagents}

All the chemicals and reagents used in this experiment, including cordycepin (MW=251.2 g/ mol, 3-4,5-dimethyl-2-thiazolyl-2,5-diphenyl-2H-tetrazoliu $\mathrm{m}$ bromide (MTT), dimethyl sulfoxide (DMSO), 2', $7^{\prime}-$ dichlorodihydrofluorescein diacetate (DCFHDA), Hydrogen peroxide $\left(\mathrm{H}_{2} \mathrm{O}_{2}\right)$ and amylase activity assay kits, were purchased from Sigma-Aldrich Co. (St. Louis, MO). Dulbecco's Modified Eagle Medium (DMEM), non-essential amino acids (NAAs) and foetal bovine serum (FBS) were purchased from HyClone (Logan, UT), whereas $0.5 \%$ trypsin-EDTA and L-glutamine were obtained from Gibco (Gibco, CA, USA).

\section{Cell culture}

HSG cell line used in this study was obtained from the American Type Culture Collection (ATCC® HTB-41 $41^{\mathrm{TM}}$, Manassas, VA, USA). Cells were cultured in a DMEM medium supplemented with $10 \%(\mathrm{v} / \mathrm{v})$
FBS, 1\% (v/v) NAAs, 1\% (v/v) L-glutamine and 1\% $(\mathrm{v} / \mathrm{v})$ antibiotics (penicillin-streptomycin). Cells were cultured at $37{ }^{\circ} \mathrm{C}$ under an atmosphere of $5 \% \mathrm{CO}_{2}$ with $95 \%$ humidity. The culture medium was replaced thrice a week.

\section{Determination of cell viability}

Cell viability was evaluated by MTT assay. Briefly, HSG cells were seeded into 96-well tissue culture plates at a density of $1 \times 10^{4}$ cells/well overnight, then the cells were treated in three different experiments; 1) treated with various concentrations of cordycepin $(6.25-50 \mu \mathrm{M})$ for 24,48 , and $72 \mathrm{~h} ; 2$ ) treated with different concentrations of $\mathrm{H}_{2} \mathrm{O}_{2}(250-2000 \mu \mathrm{M})$ to induced cell toxicity for $30 \mathrm{~min}$; 3) treated with $\mathrm{H}_{2} \mathrm{O}_{2}$ for $30 \mathrm{~min}$ and cordycepin ranging from 6.25-50 $\mu \mathrm{M}$ for $24 \mathrm{~h}$. After each treatment, the cells were washed with $100 \mu \mathrm{l}$ of $1 \times$ PBS, then $0.5 \mathrm{mg} / \mathrm{ml}$ of MTT solution in $1 \times$ PBS was added to each well and incubated at $37^{\circ} \mathrm{C}$ for $4 \mathrm{~h}$. After removal of the MTT solution, the formazan crystals were dissolved with $100 \mu \mathrm{l}$ of DMSO, and the purple formazan solution was further measured for absorbance at $570 \mathrm{~nm}$ using a microplate reader (BMG Labtech, Ortenbreg). The percentage of cell viability was calculated according to the following equation:

$$
\% \text { Cell viability }=\frac{A}{B} \times 100
$$

where A was the absorbance of OD of the treated group, and $\mathrm{B}$ was the absorbance of $\mathrm{OD}$ of the untreated group.

\section{Determination of ROS generation}

Intracellular ROS generation was determined by DCFH-DA assay. Briefly, after the seeding of HSG cells, the cells were incubated with $500 \mu \mathrm{M} \mathrm{H}_{2} \mathrm{O}_{2}$ for 30 min to induce oxidative stress in cells, then washed with 1× PBS and added to cordycepin at various concentrations for $24 \mathrm{~h}$. After being exposed to cordycepin, the cells were stained with $20 \mu \mathrm{M}$ DCFH-DA at $37^{\circ} \mathrm{C}$ for 30 min in the dark. Afterwards, the fluorescence intensity was measured at an excitation/emission of $485 / 535 \mathrm{~nm}$ using a fluorescence microplate reader (Thermo Scientific Varioskan, USA).

\section{RT-PCR analysis}

After $24 \mathrm{~h}$, total RNA was extracted from untreated and treated HSG cells in each well using the NucleoSpin RNA kit (Macherey-Nagel, Dueren, Germany), following the manufacturer's instructions. Complementary DNA was synthesized from $1 \mu \mathrm{g}$ of total RNA using the ReverTra Ace qPCR Master Mix kit (Toyobo CO., LTD., Japan), according to the manufacturer's instructions. PCR analysis was performed to determine the expression of 
salivary-specific genes, alpha-amylase 1 (AMY1A) and aquaporin-5 (AQP5), the expression of antioxidant genes, superoxide dismutase (SOD1), catalase (CAT), glutathione peroxidase (GPX1), and the expression of apoptotic genes, caspase-3 (CASP-3) and B-cell leukemia/lymphoma 2 (BCL-2). The mRNA levels of glyceraldehyde-3-phosphate dehydrogenase (GAPDH) were employed as internal controls. The primer sequences and RT-PCR conditions were shown in Table 1. The PCR products were identified by electrophoresis on $1.5 \%$ agarose gel and visualized by ethidium bromide staining. The mRNA band density of each gene was analyzed and quantified using densitometer and ImageJ software from the $\mathrm{NIH}$ website and shown as the mean \pm SD of the results from three independent experiments. Each band image was calculated for the total band density. The relative density of genes of interests and GAPDH was calculated by dividing the density of each gene by the density of GAPDH of the same sample. Lastly, the relative gene expression for the treated group was plotted as a fold-change normalized to the untreated control.

\section{Immunofluorescence staining}

Cells were grown on the surface of coverslips in 24-well plates until a confluence of $80 \%$. After being treated with cordycepin, cells were fixed with $4 \%$ paraformaldehyde (PFA) solution for $30 \mathrm{~min}$ at room temperature and rinsed with $1 \times$ PBS twice. Cells were permeabilized and blocked in blocking buffer containing $1 \%$ bovine serum albumin (BSA), $1 \%$ Triton X-100 of $1 \times$ PBS at $4{ }^{\circ} \mathrm{C}$ for $1 \mathrm{~h}$ for amylase and $4 \%$ BSA, $0.1 \%$ Triton X-100 of $1 \times$ PBS at $4{ }^{\circ} \mathrm{C}$ for 30 min for AQP5. After cell permeabilization, the cells were stained into each well, then incubated overnight at $4{ }^{\circ} \mathrm{C}$ with anti-alpha-amylase (anti-AMY) antibody
(1:100 dilution; Santa Cruz Biotechnology Inc.) and ant-aquaporin-5 (anti-AQP5) antibody (1:100 dilution; Sigma-Adrich Co.), then washed with $1 \times$ PBS twice. After being washed with PBS, the cells were incubated at room temperature for $1 \mathrm{~h}$ with Rhodamine Red-X goat anti-mouse immunoglobulin G (IgG) 1:500 dilution; Invitrogen) for anti-AMY or AlexaFluor 488 goat anti-rabbit IgG (1:1000 dilution; Invitrogen) for anti-AQP5. Lastly, the cells were incubated with $4 \mu \mathrm{l}$ of 4'6-diamidino-2-phenylindole (DAPI) (Invitrogen) for nuclear staining and observed under a ZOE ${ }^{\mathrm{TM}}$ Fluorescent Cell Imager (Bio-rad, CA, USA). The fluorescence intensity was quantified by ImageJ software. With RGB images, results are calculated using brightness values by the software will convert the RGB pixels to brightness values. To rule out the bias during the determination, we selected two areas of interest with approximately similar cell numbers represented by DAPI nuclear staining. All measurements of each image were set with the same parameters including the subtraction of fluorescence background. The fluorescence intensity was presented as a fold change which was relative to the untreated (control) group.

\section{Amylase secretion}

Amylase secretion was measured by biochemical assay. After cell culture periods, the culture medium was collected from each well. Amylase secretion was measured using the amylase activity assay kit (Sigma-Andrich Co.), according to the manufacturer's protocol. Amylase activity was measured using a microplate reader at $405 \mathrm{~nm}$. The kinetic reaction of amylase activity was calculated from the change in absorbance per $30 \mathrm{~s}$ for $2 \mathrm{~h}$.

Table 1. PCR conditions and primers used in RT-PCR analysis

\begin{tabular}{|c|c|c|c|c|c|}
\hline Genes & Direction & Primer sequences $\left(5^{\prime} \rightarrow 3^{\prime}\right)$ & Annealing Temperature $\left({ }^{\circ} \mathrm{C}\right)$ & Cycles & Product size (bp) \\
\hline \multirow[t]{2}{*}{$\overline{A M Y 1 A}$} & Forward & AATTGATCTGGGTGGTGAGC & 52 & 35 & 474 \\
\hline & Reverse & CTTATTTGGCGCCATCGATG & & & \\
\hline \multirow[t]{2}{*}{ AQP5 } & Forward & СCTGTCCATTGGCCTGTCTGTCAC & 56 & 40 & 249 \\
\hline & Reverse & GGCTCATACGTGCCTTTGATGATG & & & \\
\hline \multirow[t]{2}{*}{ CAT } & Forward & TCCGGGATCTTTTTAACGCCATTG & 55 & 30 & 362 \\
\hline & Reverse & TCGAGCACGGTAGGGACAGTTCAC & & & \\
\hline \multirow[t]{2}{*}{ SOD1 } & Forward & CTAGCGAGTTATGGCGAC & 52 & 30 & 224 \\
\hline & Reverse & CATTGCCCAAGTCTCCCA C & & & \\
\hline \multirow[t]{2}{*}{ GPX1 } & Forward & CGCCAAGAACGAAGAGATTC & 54 & 30 & 272 \\
\hline & Reverse & CAACATCGTTGAGACACA C & & & \\
\hline \multirow[t]{2}{*}{ Caspase -3} & Forward & TTTGTTTGTGTGCTTCTGAGCC & 54 & 40 & 279 \\
\hline & Reverse & ATTCTGTTGCCACCTTTCGG & & & \\
\hline \multirow[t]{2}{*}{$B C L-2$} & Forward & CGCATCAGGAAGGCTAGAGT & 53 & 40 & 189 \\
\hline & Reverse & AGCTTCCAGACATTCGGAGA & & & \\
\hline \multirow[t]{2}{*}{ GAPDH } & Forward & ACCTGACCTGCCGTCTAGAA & 54 & 35 & 247 \\
\hline & Reverse & TCCACCACCCTGTTGCTGTA & & & \\
\hline
\end{tabular}



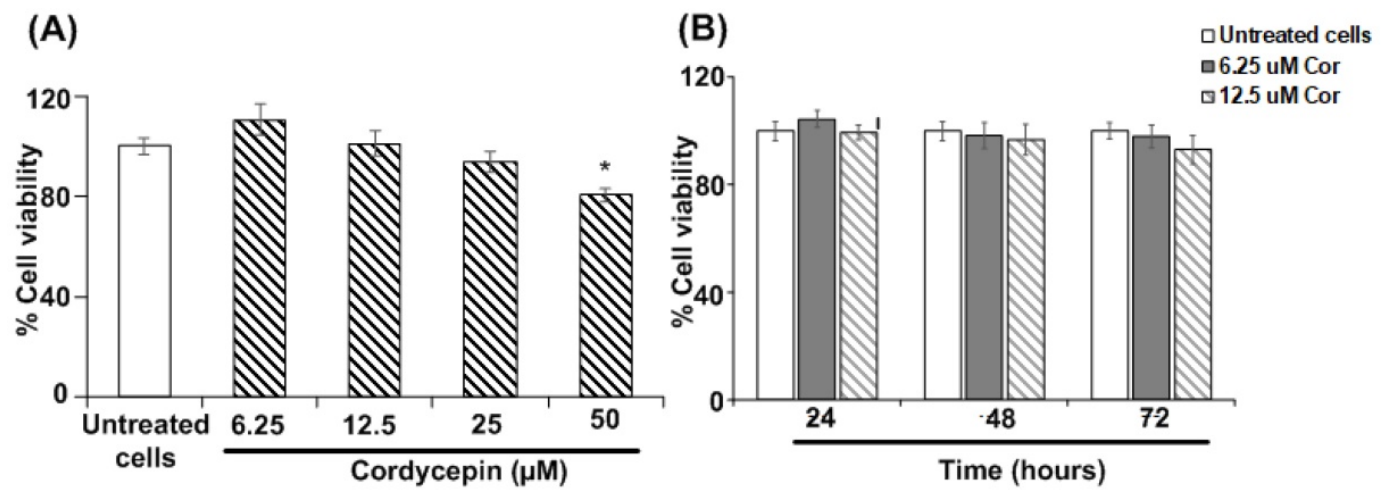

(C)

(D)
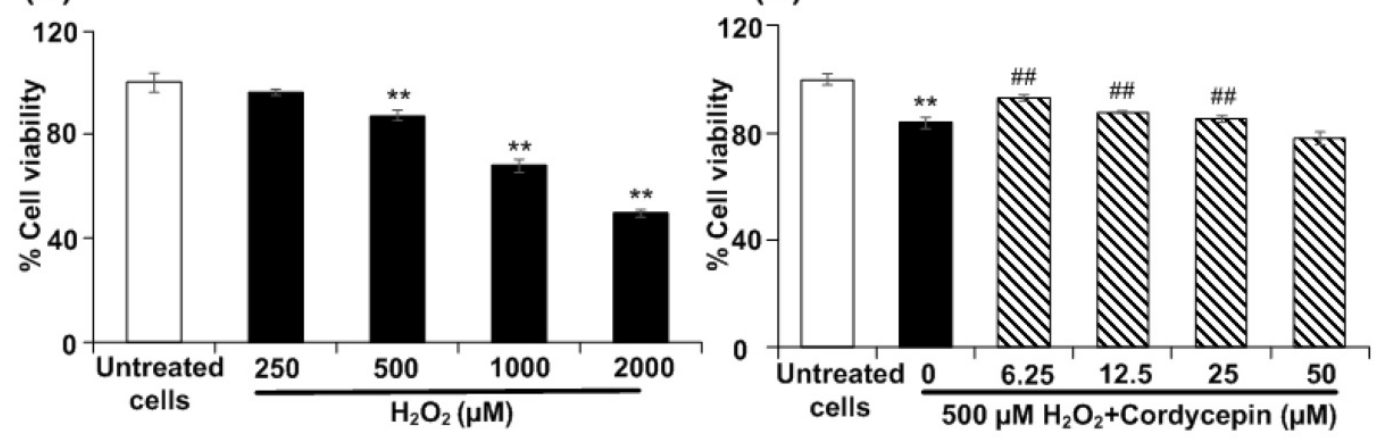

(E)

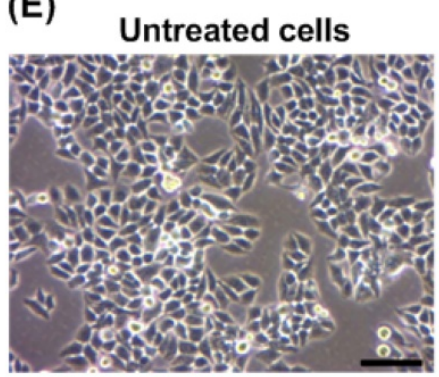

$500 \mu \mathrm{M} \mathrm{H}_{2} \mathrm{O}_{2}$
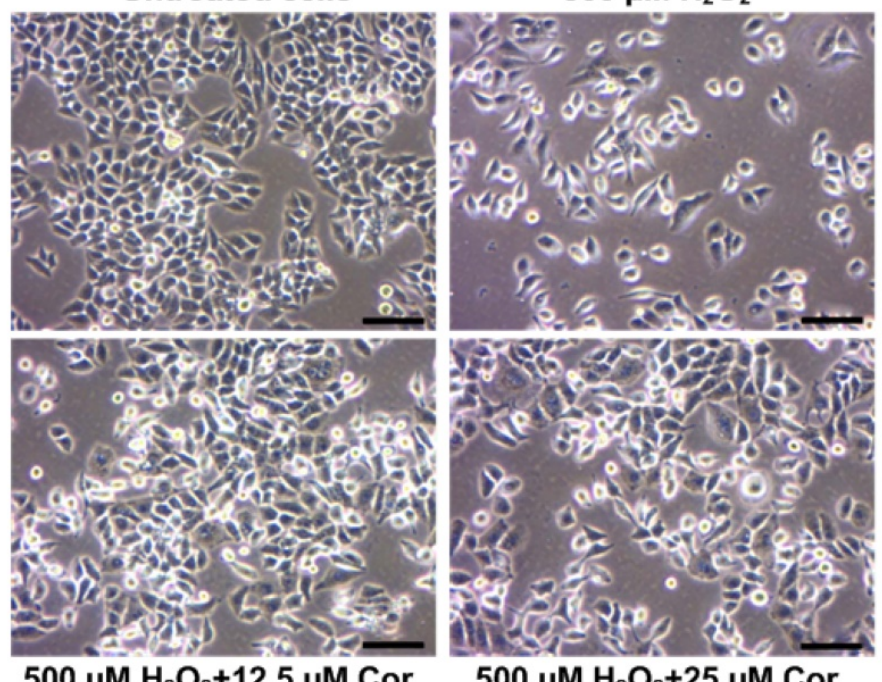

$500 \mu \mathrm{M} \mathrm{H}_{2} \mathrm{O}_{2}+6.25 \mu \mathrm{M}$ Cor

$500 \mu \mathrm{M} \mathrm{H}_{2} \mathrm{O}_{2}+12.5 \mu \mathrm{M}$ Cor
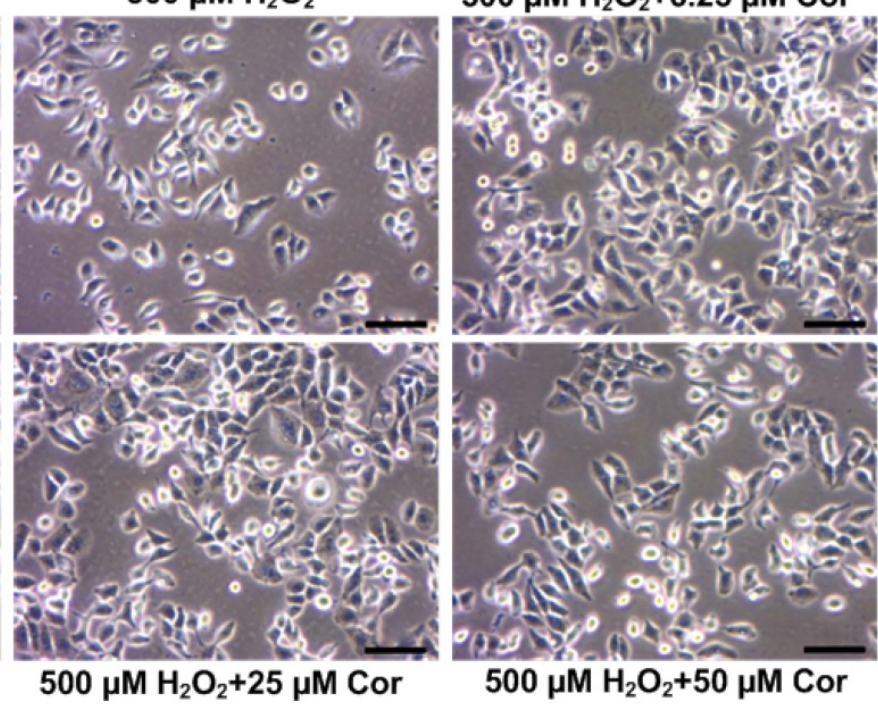

Figure 1. Cordycepin prevented HSG cells from $\mathrm{H}_{2} \mathrm{O}_{2}$-induced cell toxicity. Cells were treated with various concentrations of cordycepin (6.25-50 $\left.\mu \mathrm{M}\right)$ for 24,48 and $72 \mathrm{~h}(\mathbf{A}, \mathbf{B})$ and different concentrations of $\mathrm{H}_{2} \mathrm{O}_{2}(250-2000 \mu \mathrm{M})$ were used to induced cell toxicity for a 30 min culture period (C). The post-treatment of HSG cells under 500 $\mu \mathrm{M} \mathrm{H}_{2} \mathrm{O}_{2}$ for $30 \mathrm{~min}$ and cordycepin ranging from 6.25-50 $\mu \mathrm{M}$ for $24 \mathrm{~h}$ was measured by MTT assay (D). Cell morphology of $\mathrm{HSG}$ cells exposed to $\mathrm{H}_{2} \mathrm{O}_{2}$ and cordycepin under an inverted microscope (E). The scale bar represents $20 \mu \mathrm{m}$. ${ }^{*} p<0.05$ and $* * p<0.01$ compared to the untreated group, and ${ }^{*} p<0.01$ compared to the $\mathrm{H}_{2} \mathrm{O}_{2}$ group.

\section{Statistical analysis}

Data were presented as the means \pm SDs of three independent measurements $(\mathrm{n}=3)$. All analyses were performed using the Statistical Package for the Social Sciences (SPSS) software 23.0 for Windows. For comparison of the treatments, statistical significance was assessed by student's t-test to compare means from two independent sample groups at $P$-value $(p<0.05)$.

\section{Results}

\section{Cordycepin prevents against $\mathrm{H}_{2} \mathrm{O}_{2}$-induced toxicity in HSG cells}

In this study, we first performed the cytotoxicity test of cordycepin on HSG cells. The HSG cells were treated with various concentrations of cordycepin $(6.25-50 \mu \mathrm{M})$ for 24,48 , and $72 \mathrm{~h}$ and then measured by MTT assay. As shown in Figure 1A, the HSG cells 
exposed to most concentrations of cordycepin at $24 \mathrm{~h}$ did not show their viability alteration. Nevertheless, the highest cordycepin concentration $(50 \mu \mathrm{M})$ was slightly toxic in HSG cells $(19.66 \% \pm 2.45)$. These suggests that cordycepin especially at low concentrations did not display a toxic effect to the HSG. In addition, the cell viability at different time points $(24,48$, and $72 \mathrm{~h})$ showed that \% cell viability of HSG remains unchanged at various time points, indicating that cordycepin had no proliferative effects on HSG cells (Figure 1B). The percentage of viable HSG cells was considerably decreased upon exposure to $\mathrm{H}_{2} \mathrm{O}_{2}$ (Figure 1C), indicating cytotoxicity. Furthermore, we investigated the preventive effects of cordycepin against $\mathrm{H}_{2} \mathrm{O}_{2}$-induced cell toxicity. The post-treatment group with cordycepin under $\mathrm{H}_{2} \mathrm{O}_{2}$ revealed significantly increased cell viability when compared to the $\mathrm{H}_{2} \mathrm{O}_{2}$ group (Figure 1D). Moreover, the post-treatment group with cordycepin in HSG cells showed cell morphology similar to that of the untreated group (Figure 1E).

\section{Cordycepin promotes the expression of salivary genes in $\mathrm{H}_{2} \mathrm{O}_{2}$-induced $\mathrm{HSG}$ cells}

HSG cells were cultured in each concentration of cordycepin treatment for a $24 \mathrm{~h}$ period; salivary gene expression was then comparatively assessed. The salivary-specific gene expression, $A M Y 1 A$ and $A Q P 5$, of the cultured HSG cells was determined by RT-PCR analysis. The band intensities of mRNA expression of $A M Y 1 A$ and AQP5 in each cordycepin concentrationtreated HSG cells were demonstrated (Figure 2A). In cordycepin concentrations $(6.25,12.5,25 \mu \mathrm{M})$, the relative expression of $A M Y 1 A$ gradually increased as compared to that found in the untreated group. In particular, $12.5 \mu \mathrm{M}$ of cordycepcin significantly increased $A M Y 1 A$ expression (Figure 2B). The expression of AQP5 detected in the $12.5 \mu \mathrm{M}$ of cordycepin group was also higher than that detected in the untreated group (Figure 2C). Interestingly, the increase in salivary-specific gene expression observed among the cells cultured in the cordycepin treatments were much different from one another. In addition, cordycepin had protective effect on $\mathrm{H}_{2} \mathrm{O}_{2}$-induced HSG cell dysfunction, the gene expression demonstrated that all cordycepin concentrations significantly increased the levels of $A M Y 1 A$ and $A Q P 5$ in $\mathrm{H}_{2} \mathrm{O}_{2}$-induced HSG cells compared to the induced cells without the cordycepin treatment (Figures 2D-F), suggesting that cordycepin could rescue the salivary function after oxidative stress exposure).

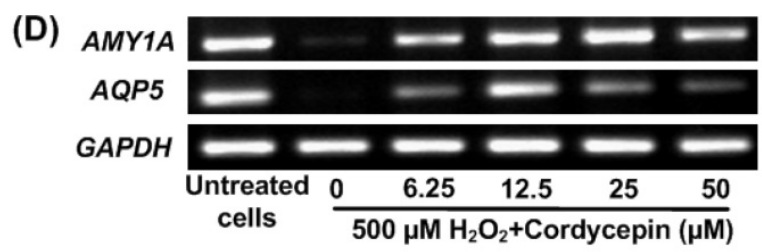

$(\mathrm{E})$

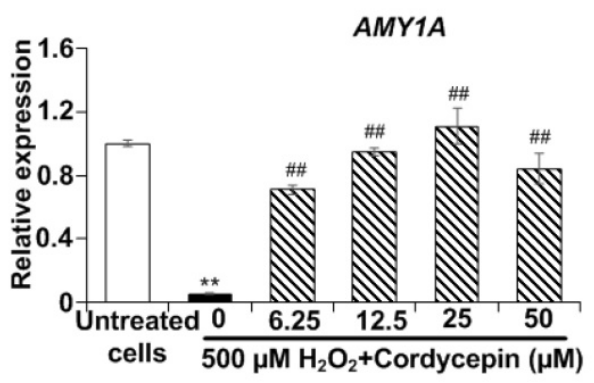

$(\mathrm{F})$

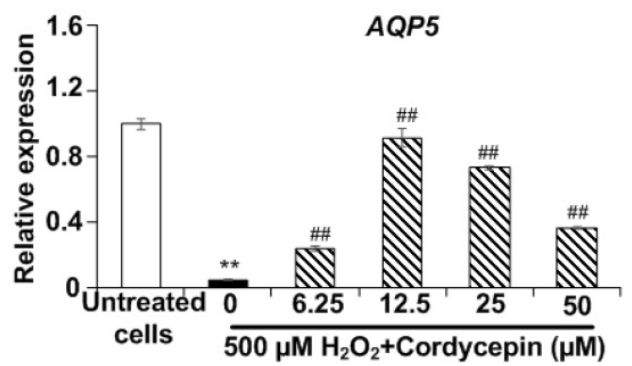

Figure 2. Cordycepin upregulated salivary marker genes in $\mathbf{H}_{2} \mathbf{O}_{2}$-induced $\mathbf{H S G}$ cells. Cells were treated with cordycepin ranging from $6.25 \mu \mathrm{M}$ to $50 \mu \mathrm{M}$ for $24 \mathrm{~h}$. The mRNA expression for AMYIA and AQP5 were analysed by RT-PCR (A-C). Cordycepin promoted AMYIA and AQP5 expression in HSG cells exposed to $\mathrm{H}_{2} \mathrm{O}_{2}$ for 30 min (D-F). The relative mRNA expression levels of AMYIA (B-E) and AQP5 (C-F) genes were evaluated by image J NIH software and normalized with GAPDH gene. Gel electrophoresis results are from one representative experiment and bar charts are derived from analysis of relative expression from three independent experiments. $* p<0.05$ and ${ }^{* *} p<0.01$ compared to the untreated group, and ${ }^{\#} p<0.01$ compared to the $\mathrm{H}_{2} \mathrm{O}_{2}$ group. 


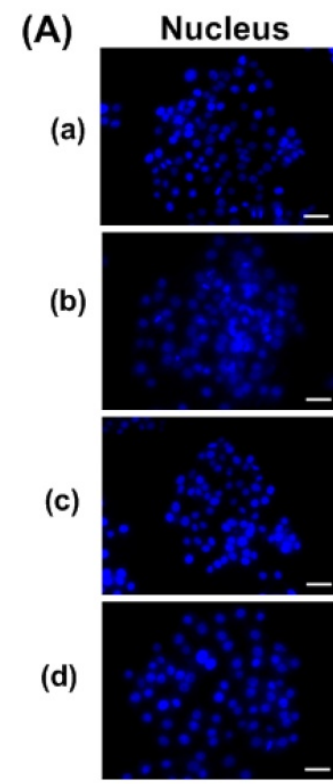

(B)

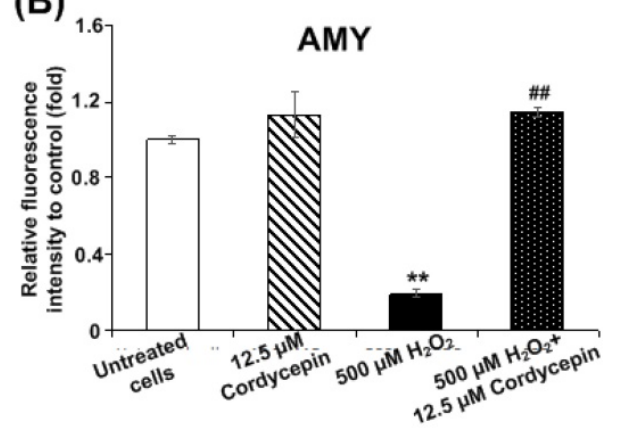

(C)

(a)
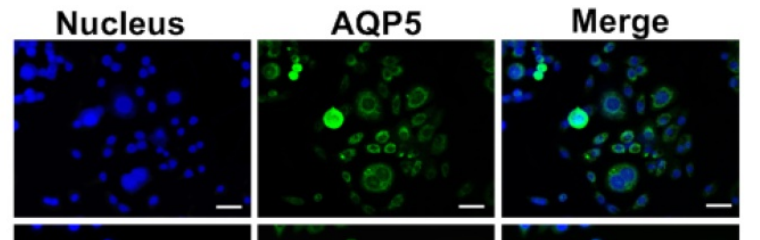

(b)

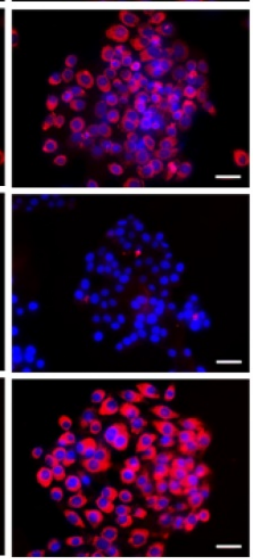

(c)

(d)

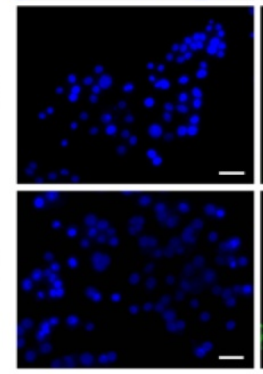

(D)

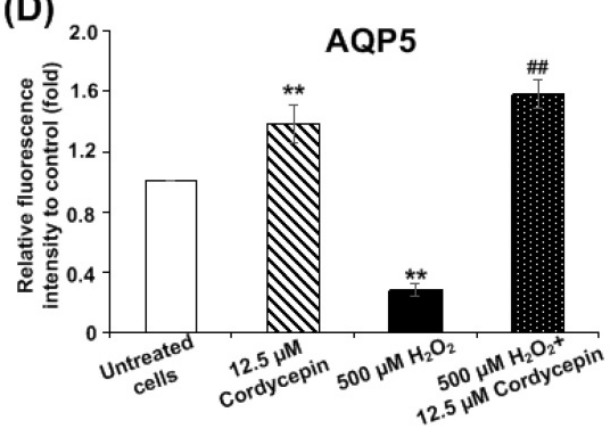

Figure 3. Cordycepin rescued the expression of salivary proteins in $\mathbf{H}_{2} \mathbf{O}_{2}$-induced $\mathbf{H S G}$ cells. Both AMY (A) and AQP5 (C) protein expression in HSG cells were determined by immunofluorescence. Cells were treated with cordycepin at either $0 \mu \mathrm{M}$ (a) or $12.5 \mu \mathrm{M}$ (b) for $24 \mathrm{~h}$, treatment with $500 \mu \mathrm{M} \mathrm{H} \mathrm{H}_{2} \mathrm{O}_{2}$ for 30 min without (c) or with $12.5 \mu \mathrm{M}$ cordycepin for $24 \mathrm{~h}$ (d). The relative fluorescence intensity of both AMY (B) and AQP5 (D) proteins in cordycepin-treated HSG cells were normalized with the untreated group. Immunofluorescence images are from one representative experiment. Bar charts were expressed as mean \pm SD from three independent experiments. The scale bar represents $40 \mu \mathrm{m}$. ${ }^{* *} p<0.01$ compared to the untreated group, and ${ }^{*} p<0.01$ compared to the $\mathrm{H}_{2} \mathrm{O}_{2}$ group.

\section{Cordycepin alters both AMY and AQP5 protein expressions in $\mathbf{H}_{\mathbf{2}} \mathrm{O}_{2}$-induced $\mathrm{HSG}$ cells}

The expression of AMY and AQP5 proteins in HSG cells under $\mathrm{H}_{2} \mathrm{O}_{2}$-induced oxidative stress was investigated using immunofluorescence assay. The effect of cordycepin stimulation on AMY protein expression was indicated (Figure 3A). The relative fluorescence intensity revealed that no significant differences were observed in HSG cells treated with either cultured medium or cordycepin. Intriguingly, $\mathrm{H}_{2} \mathrm{O}_{2}$-induced oxidative stress revealed a significant reduction in AMY protein expression when compared to the untreated group. Compared to the $\mathrm{H}_{2} \mathrm{O}_{2}$ group, the post-treatment group with cordycepin showed a dramatic increase of AMY protein expression in HSG cells (Figure 3B). The expression of AQP5 protein in HSG cells treated with either cordycepin, $\mathrm{H}_{2} \mathrm{O}_{2}$ or cordycepin post-treatment was demonstrated (Figure $3 C)$. The relative fluorescence of AQP5 was also significantly increased in HSG cells treated with cordycepin. However, compared to the untreated group, the AQP5 protein expression of $\mathrm{H}_{2} \mathrm{O}_{2}$-induced HSG cells was extremely decreased. Noticeably, the cells post-treated with cordycepin were found to have significantly increased levels of AQP5 protein, indicating that under $\mathrm{H}_{2} \mathrm{O}_{2}$-induced oxidative stress, cordycepin could stimulate the expression of both AMY and AQP5 (Figures 3B \& D). These results suggest that cordycepin could rescue both AMY and AQP5 protein expressions under $\mathrm{H}_{2} \mathrm{O}_{2}$-induced oxidative stress in HSG cells.

\section{Cordycepin attenuates against intracellular ROS generation and affects apoptotic gene expression in $\mathbf{H}_{\mathbf{2}} \mathrm{O}_{2}$-induced HSG cells}

Next, we investigated the effect of cordycepin against $\mathrm{H}_{2} \mathrm{O}_{2}$-induced intracellular ROS generation in HSG cells using DCFH-DA fluorescence assay. The fluorescence intensity of DCFH-DA was considerably increased by $500 \mu \mathrm{M} \mathrm{H}_{2} \mathrm{O}_{2}$ when compared to the untreated group, indicating that $\mathrm{H}_{2} \mathrm{O}_{2}$ enables to generate intracellular ROS. However, the posttreatment with cordycepin effectively reduced 
intracellular ROS generation in HSG cells (Figure 4A). To confirm the preventive effects of cordycepin in HSG cells, the expressions of antioxidant genes (i.e. SOD1, CAT and GPX1) and apoptotic genes were evaluated. The band intensities of mRNA expression of these antioxidant genes were upregulated in HSG cells cultured in each concentration of cordycepin post-treatment (Figure 4B \& D). The relative expression of CAT and SOD1 were increased significantly in all concentrations of cordycepin whereas that of GPX1 were increased significantly in certain concentrations as compared to that found in the untreated group (Figure 4D). Similarly, we also found that, $\mathrm{H}_{2} \mathrm{O}_{2}$ induced up-regulation of apoptotic gene, caspase-3 and down-regulated BCL-2 gene expression. Significantly, a decrease in the level of caspase- 3 and an increase in $B C L-2$ in $\mathrm{H}_{2} \mathrm{O}_{2}$-induced HSG cells after post-incubation with cordycepin were demonstrated (Figure 4C \& E). This may indicate the anti-apoptotic activity of cordycepin on $\mathrm{H}_{2} \mathrm{O}_{2}$-induced HSG cells.

\section{Cordycepin stimulates the amylase secretion from $\mathrm{HSG}$ cells under $\mathrm{H}_{2} \mathrm{O}_{2}$-induced oxidative stress}

The amounts of amylase secreted from the HSG

(A)

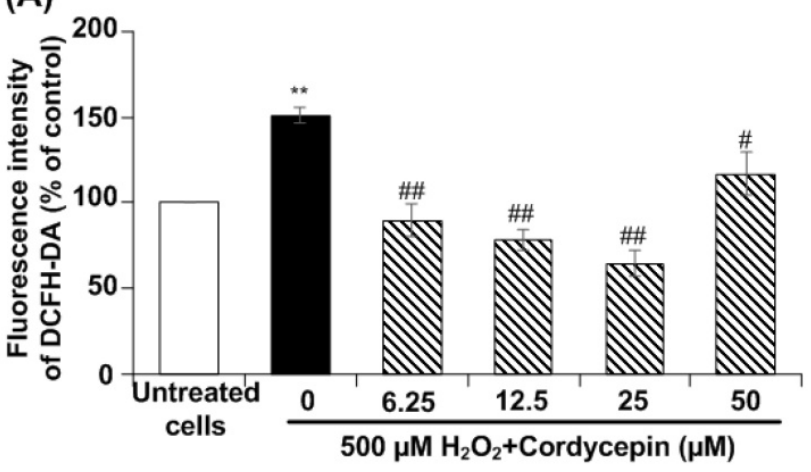

(D)

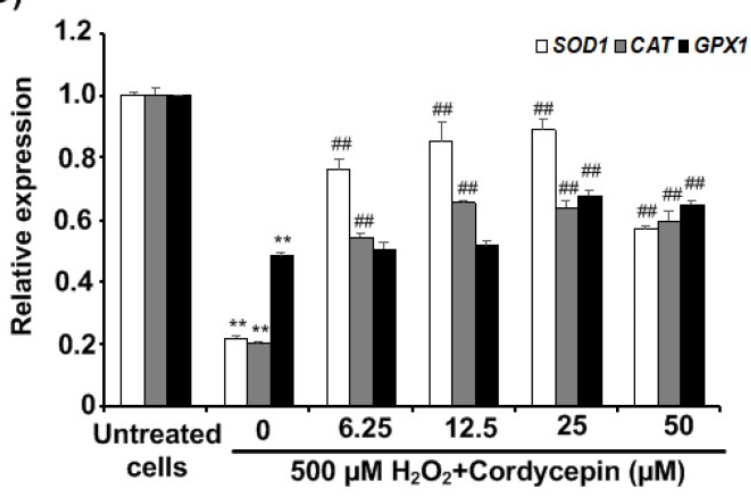

cells cultured in each cordycepin concentration were reported (Figure 5). Compared to the untreated group, specific concentrations of cordycepin treatment could stimulate the cells to secrete more amylase after short and long-term culture periods. For the short-term culture periods, cordycepin stimulated amylase secretion, with the high levels during $812 \mathrm{~h}$. The $12.5 \mu \mathrm{M}$ of cordycepin treated HSG cells showed the highest level of amylase secretion at $8 \mathrm{~h}$. However, at $24 \mathrm{~h}$, the secretion of amylase was dropped in all groups (Figure 5A). It is also noted that amylase secretion from the cells cultured in $6.25,12.5$ and 25 $\mu \mathrm{M}$ of cordycepin (1-5 days) were increased but statistically insignificant (Figure 5B). To further study the effect of cordycepin in amylase secretion of HSG cells, cordycepin was used to treat $\mathrm{H}_{2} \mathrm{O}_{2}$-exposed HSG cells. As expected, after 30 min of $\mathrm{H}_{2} \mathrm{O}_{2}$ treatment, the amylase secretion in the culture medium was suddenly decreased. Surprisingly, the amount of amylase was significantly increased in the culture medium when cordycepin was used for post-treatment (Figure 5C).

(B)

(C)
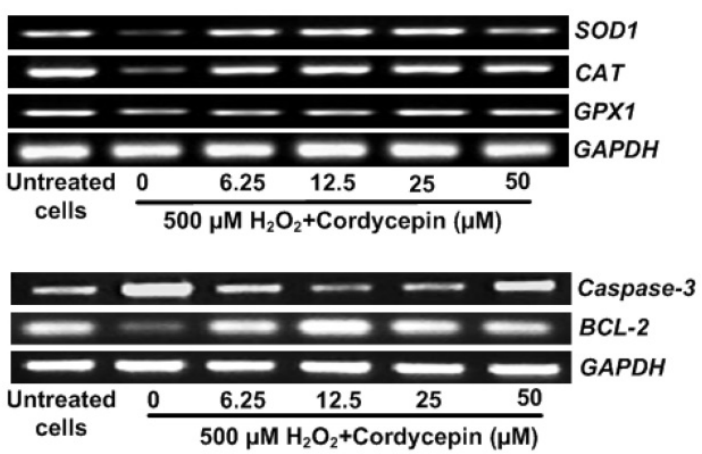

(E)

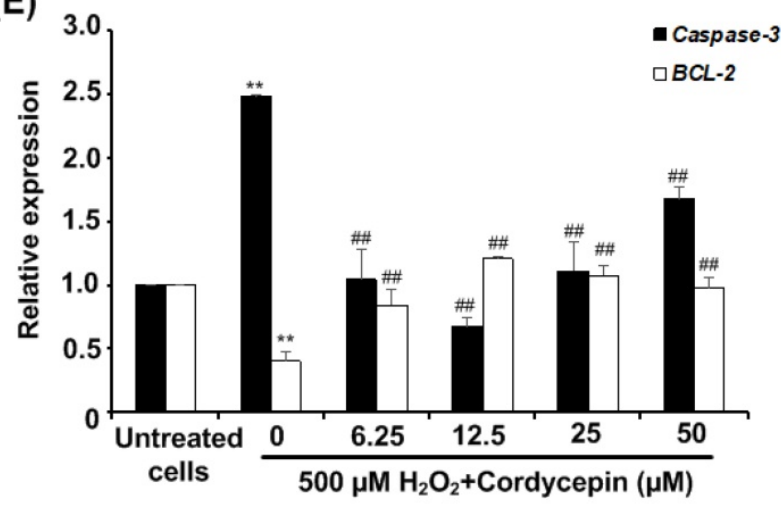

Figure 4. Cordycepin attenuated $\mathrm{H}_{2} \mathrm{O}_{2}$-induced intracellular ROS generation in HSG cells. Cells were induced with $500 \mu \mathrm{M} \mathrm{H}_{2} \mathrm{O}_{2}$ for 30 min and exposed to cordycepin ranging from 6.25-50 $\mu \mathrm{M}$ for $24 \mathrm{~h}$. The relative fluorescence intensity of DCFH-DA was determined by DCFH-DA assay (A). The mRNA expression for antioxidant genes, SODI, CAT, and GPXI (B) and apoptotic genes including caspase-3 and BCL-2 (C) were analysed by RT-PCR. The relative mRNA expression levels of SODI, CAT and GPXI (D), Caspase-3 and BL-2 (E) genes were evaluated by image J NIH software and normalized with GAPDH. Gel electrophoresis are from one representative experiment and bar charts are derived from analysis of relative expression from three independent experiments. $* * p<0.01$ compared to the untreated group; ${ }^{*} p<0.01$ and \#\# ${ }^{*}<0.01$ compared to the $\mathrm{H}_{2} \mathrm{O}_{2}$ group. 


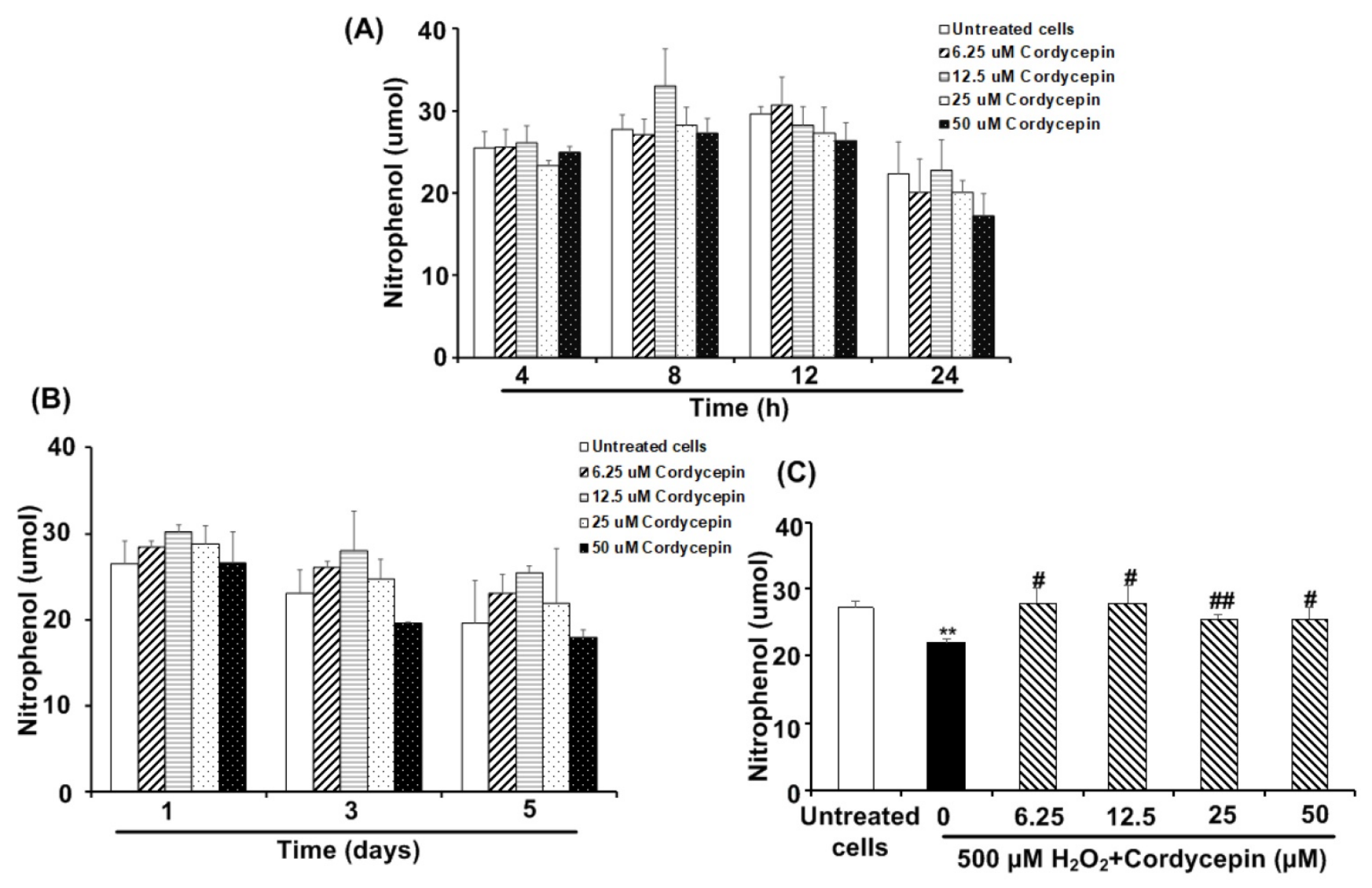

Figure 5. Cordycepin increased amylase secretion in $\mathbf{H}_{2} \mathbf{O}_{2}$-induced $\mathbf{H S G}$ cells. Cells were treated with various concentrations of cordycepin for short-term culture

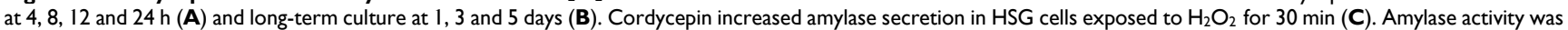
kinetically measured in a cultured medium of HSG cells exposed to $\mathrm{H}_{2} \mathrm{O}_{2}$ without or with cordycepin treatment for $24 \mathrm{~h}$. Data are represented as mean $\pm \mathrm{SD}$ ( $\mathrm{n}=3$ ). $* * 0<0.01$ compared to the untreated group, and ${ }^{\#} p<0.05$ and ${ }^{m} p<0.01$ compared to the $\mathrm{H}_{2} \mathrm{O}_{2}$ group.

\section{Discussion}

Xerostomia is a common side effect of numerous medications and other therapies, especially found in patients that have received radiotherapy for the treatment of head and neck cancer and in elderly individuals [21, 22]. Current treatments for xerostomia include salivary substitutes, hyperbaric oxygen and gene therapy as well as salivary stimulants such as pilocarpine (a non-selective muscarinic receptor agonist) [23-25]. However, these treatments still have the potential risk for undesirable adverse effects [26]. The major bioactive compound of Cordyceps sp. is cordycepin, also known as 3deoxyandenosine, which has various pharmaceutical properties including antitumor, anticancer, antiinflammatory, immunomodulatory and antioxidant activities [13, 14, 27]. This study indicated that cordycepin could stimulate the gene and protein expression of salivary markers and amylase secretion, while it reduced intracellular ROS generation in HSG cells via anti-oxidant and anti-apoptotic activities. The protective effect of cordycepin could enhance the $\mathrm{H}_{2} \mathrm{O}_{2}$-induced HSG cells to survive and revive the functions as a vital saliva-producing cells.
Amylase (AMY) and aquaporin-5 (AQP5) are two important specific markers for functional salivary glands [28]. Amylase, which is encoded by AMY1A gene, is one of the major protein components of saliva and is a digestive enzyme for calcium binding responsible for starch hydrolysis [29-31]. In addition, aquaporin-5, which is encoded by AQP5 gene, is a water-selective channel protein expressed in the apical membrane of epithelial cells of serous acini in the salivary glands [32-35]. The osmolality and the concentration of electrolytes in salivary fluid secretion are directly controlled by AQP5 protein. In this study, cordycepin enhanced the expression of both the $A M Y 1 A$ and AQP5 genes in HSG cells. Although the effective dose to stimulate $A M Y 1 A(25 \mu \mathrm{M})$ and $A Q P 5$ $(12.5 \mu \mathrm{M})$ genes was different, it did not show a much difference in a fold-change expression. The concentration at $12.5 \mu \mathrm{M}$ of cordycepin was chosen for further study since we expected the most effective result with the lower concentration of cordycepin. This concentration showed an increasing effect in $A M Y 1 A$ and AQP5 for both gene and protein levels. This is promising since the previous study showed that AQP5 is one of key proteins to cause xerostoma. In addition, a study has previously reported that high 
expression of $A Q P 5$ leads to an increase in a salivary amylase level in diabetes induced xerostomia rats [36].

Salivary gland hypofunction and reduced expression of $A Q P 5$ are the oxidative stresses leading to xerostomia [2]. Our results showed that cordycepin could promote the expression of AQP5 genes, suggesting that the water channels are opened by cordycepin treatment after administration of $\mathrm{H}_{2} \mathrm{O}_{2}$. During the study of the expression of protein levels, the reduction in expression of AMY and AQP5 protein levels have been observed in HSG cells exposed to $\mathrm{H}_{2} \mathrm{O}_{2}$-induced oxidative stress. However, AMY and AQP5 protein levels were significantly increased in cordycepin-treated HSG cells after $\mathrm{H}_{2} \mathrm{O}_{2}$ administration. These results suggested that the oxidative stress related with xerostomia-induced hyposalivary function can be reversed effectively by treatment with cordycepin. Previous studies have proposed that the mechanism of cordycepin in salivary gland cells might involve several pathways, such as sodium/hydrogen exchanger-1 (NHE1) activity [37], c-Jun N-terminal kinase (JNK) phosphorylation [38] and protein disulphide isomerase (PDI) [39].

ROS generation is a major cause of oxidative stress, which is harmful to the biomolecules inducing the pathology in the body, causing age-related cell damage. Oxidative stress is a main cause of cellular damage in several diseases, including xerostomia [40, 41]. In addition to therapeutic interventions, bioactive compounds with antioxidant activity have been reported to be capable of protecting cells from oxidative stress [42, 43]. The bioactive compound cordycepin has been previously reported to be effective against oxidative and endoplasmic reticulumstress by reducing intracellular ROS generation in vitro $[15,44]$. Wang et al. revealed that cordycepin could prevent human bone marrow mesenchymal stem cells (BM-MSCs) from $\mathrm{H}_{2} \mathrm{O}_{2}$-induced inhibition of osteogenesis [18]. Moreover, cordycepin protected against neuron cell death in PC12 and C6 glial cells from oxidative stress-induced neurotoxicity $[19,20]$. In animal models, cordycepin treatment decreased oxidative damage and boosted the differentiation of BM-MSCs [18]. To examine cells under oxidative stress, intracellular ROS generation and the expression of antioxidant genes, which are widely used as markers for oxidative stress, were determined. In this study, we observed that ROS generation was increased by $\mathrm{H}_{2} \mathrm{O}_{2}$-induced oxidative stress in HSG cells; nevertheless, it was effectively alleviated by cordycepin treatment. To confirm intracellular ROS generation, we determined the effect of cordycepin through the antioxidant gene expression, SOD1, CAT and GPX1 in the $\mathrm{H}_{2} \mathrm{O}_{2}$-induced HSG cells. SOD1 is an important endogenous antioxidant enzyme. It catalyzes the dismutation of superoxide anion free radicals to hydrogen peroxide and oxygen and acts as the first enzyme in defense of cell death from ROS [45]. CAT is used in the reduction of hydrogen peroxide to water and oxygen, while GPX1 is the intracellular enzyme used to reduce hydrogen peroxide to water and lipid peroxides [46]. Our results showed that the post-treatment with cordycepin considerably upregulated the expression of the SOD1, CAT and GPX1 genes in HSG cells induced by $\mathrm{H}_{2} \mathrm{O}_{2}$. Furthermore, we also demonstrated that, posttreatment with cordycepin significantly decreased the expression of caspase-3, but increased BCL-2 expression in $\mathrm{H}_{2} \mathrm{O}_{2}$-induced HSG cells. Taken together, these results indicated that cordycepin could effectively block ROS generation through the anti-oxidant and anti-apoptotic activities.

The composition of saliva is $99 \%$ water and 1\% solids and protein, and it produced by the salivary glands consisting of the parotid, sublingual and submandibular glands $[47,48]$. Amylase is a major of protein component of saliva, which is synthesized and secreted by acinar cells, a major cell population in the salivary gland. Enzymatic digestion of carbohydrates is the main function of saliva working through the amylase [49]. In this study, we also determined the amylase activity of HSG cells treated with cordycepin. The higher level of amylase secretion in the HSG cells was found during 8-12 h co-culture in cordycepin while long-term culture period (1-5 day) stimulated lesser amount of amylase secretion. The pharmacokinetic research demonstrated that the half-life of cordycepin was short. Cordycepin is rapidly deaminated by adenosine deaminase and promptly metabolized to an inactive metabolite, 3 '-deoxy-hypoxanthinosine [50, 51]. It was found that cordycepin permeated the cell membrane of human endothelial-like immortalized cells (EA.hy926) cells within $30 \mathrm{~min}$ and was steady for a $3 \mathrm{~h}$ culture period [52]. Although, cordycepin are rapidly reduced and metabolized in a short period of time, a cordycepininduced unidentified compounds detected in blood and liver for over $2 \mathrm{~h}$, which might have highly specific and widespread within the body organ or tissue $[51,53,54]$. To overcome the problem of rapid elimination, a high concentration might be administered; otherwise, intracellular concentrations would be sub-therapeutic. Interestingly, we demonstrated that the amylase secretion was recovered after cordycepin treatment in HSG cells induced by $\mathrm{H}_{2} \mathrm{O}_{2}$ as well as cordycepin significantly enhanced $A M Y 1 A$ and AQP5 expression at both 
mRNA and protein levels. It is possible that recovering secretion of amylase under oxidative stress may be due to the ability of cordycepin on $A M Y 1 A$ gene and signaling pathways that are responsible for activating fluid and enzyme secretion [55]. Furthermore, cordycepin probably promotes the effective function of AQP5 gene which is the major pathway for regulating the salivary fluid secretion (water and protein) permeability in acinar cells [56, 57]. Altogether, cordycepin could help cells restoring from oxidative stress by increasing salivary secretion via an increase in AMY and AQP5 protein levels and the resulting amylase secretion. However, despite the fact that we observed significant protein expression in the cordycepin-treated group compared to the untreated group, the enzyme activity was not dramatically different compared to the protein expression. This may be described by two explanations. First, the intracellular protein expression was analysed through immunofluorescence staining whereas the protein activity was evaluated from the supernated extracellular protein. Hence, the enzymatic function of secreted amylase may be affected by the post-modification or the formation of complex to function properly. Also, the functional amount of amylase in the supernatant may influence the amylase activity [58]. Second, several previous studies have shown that the $2 \mathrm{D}$ in vitro model of salivary gland differentiation can enhance amylase expression and activity. However, the 3D model can better improve the differentiation. This latter model would help salivary gland cells to perform their function and activity better [59]. Therefore, the 2D model that we selected in this study may limit the protein function.

\section{Conclusions}

In conclusion, cordycepin could effectively protect against HSG cell death from $\mathrm{H}_{2} \mathrm{O}_{2}$-induced toxicity by reducing ROS generation via antioxidant and anti-apoptotic capacities. Furthermore, cordycepin exerts prevention by increasing both the expression of salivary marker genes and amylase secretion. Thus, these results suggest that cordycepin might be used as a new therapeutic agent and an experimental model for oral dryness.

\section{Acknowledgements}

This study was supported by the National Research Council of Thailand (SUT9-906-62-36-01), the Oral Health Research Unit, Institute of Dentistry and Institute of Agricultural Technology, Suranaree University of Technology (SUT).

\section{Competing Interests}

The authors have declared that no competing interest exists.

\section{References}

1. Bhattarai KR, Lee SW, Kim SH, et al. Ixeris dentata extract regulates salivary secretion through the activation of aquaporin-5 and prevents diabetes-induced xerostomia. J Exp Pharmacol. 2017; 9: 81-91.

2. Bhattarai KR, Lee HY, Kim SH, et al. Ixeris dentata Extract Increases Salivary Secretion through the Regulation of Endoplasmic Reticulum Stress in a Diabetes-Induced Xerostomia Rat Model. Int J Mol Sci. 2018; 19.

3. Silvestre FJ, Minguez MP, Sune-Negre JM. Clinical evaluation of a new artificial saliva in spray form for patients with dry mouth. Med Oral Patol Oral Cir Bucal. 2009; 14: E8-E11.

4. Napenas JJ, Brennan MT, Fox PC. Diagnosis and treatment of xerostomia (dry mouth). Odontology. 2009; 97: 76-83.

5. Ekström J, Khosravani N, Castagnola M, et al. Saliva and the Control of Its Secretion. 2011;p:19-47.

6. Fabian TK, Hermann P, Beck A, et al. Salivary defense proteins: their network and role in innate and acquired oral immunity. Int J Mol Sci. 2012; 13: 4295-320.

7. Nita M, Grzybowski A. The Role of the Reactive Oxygen Species and Oxidative Stress in the Pathomechanism of the Age-Related Ocular Diseases and Other Pathologies of the Anterior and Posterior Eye Segments in Adults. Oxid Med Cell Longev. 2016; 2016: 3164734.

8. Lobo V, Patil A, Phatak A, et al. Free radicals, antioxidants and functional foods: Impact on human health. Pharmacogn Rev. 2010; 4: 118-26.

9. Pham-Huy LA, He H, Pham-Huy C. Free radicals, antioxidants in disease and health. Int J Biomed Sci. 2008; 4: 89-96.

10. Young IS, Woodside JV. Antioxidants in health and disease. J Clin Pathol. 2001; 54: 176-86.

11. Kuraji M, Matsuno T, Satoh T. Astaxanthin affects oxidative stress and hyposalivation in aging mice. J Clin Biochem Nutr. 2016; 59: 79-85.

12. Yamauchi $Y$, Matsuno T, Omata K, et al. Relationship between hyposalivation and oxidative stress in aging mice. J Clin Biochem Nutr. 2017; 61: 40-6.

13. Cui JD. Biotechnological production and applications of Cordyceps militaris, a valued traditional Chinese medicine. Crit Rev Biotechnol. 2015; 35: 475-84.

14. Das SK, Masuda M, Sakurai A, et al. Medicinal uses of the mushroom Cordyceps militaris: current state and prospects. Fitoterapia. 2010; 81: 961-8.

15. Ramesh T, Yoo SK, Kim SW, et al. Cordycepin (3'-deoxyadenosine) attenuates age-related oxidative stress and ameliorates antioxidant capacity in rats. Exp Gerontol. 2012; 47: 979-87.

16. $\mathrm{Li} \mathrm{XT}, \mathrm{Li} \mathrm{HC}, \mathrm{Li} \mathrm{CB}$, et al. Protective effects on mitochondria and anti-aging activity of polysaccharides from cultivated fruiting bodies of Cordyceps militaris. Am J Chin Med. 2010; 38: 1093-106.

17. Lin $\mathrm{R}$, Liu $\mathrm{H}, \mathrm{Wu} \mathrm{S}$, et al. Production and in vitro antioxidant activity of exopolysaccharide by a mutant, Cordyceps militaris SU5-08. Int J Biol Macromol. 2012; 51: 153-7.

18. Wang F, Yin $\mathrm{P}, \mathrm{Lu} \mathrm{Y}$, et al. Cordycepin prevents oxidative stress-induced inhibition of osteogenesis. Oncotarget. 2015; 6: 35496-508.

19. Olatunji OJ, Feng Y, Olatunji OO, et al. Cordycepin protects PC12 cells against 6-hydroxydopamine induced neurotoxicity via its antioxidant properties. Biomed Pharmacother. 2016; 81: 7-14.

20. He MT, Lee AY, Park CH, et al. Protective effect of Cordyceps militaris against hydrogen peroxide-induced oxidative stress in vitro. Nutr Res Pract. 2019; 13: 279-85.

21. Hopcraft MS, Tan C. Xerostomia: an update for clinicians. Aust Dent J. 2010; 55: 238-44; quiz 353.

22. Yeh CK, Johnson DA, Dodds MW. Impact of aging on human salivary gland function: a community-based study. Aging (Milano). 1998; 10: 421-8.

23. Miranda-Rius J, Brunet-Llobet L, Lahor-Soler E, et al. Salivary Secretory Disorders, Inducing Drugs, and Clinical Management. Int J Med Sci. 2015; 12: 811-24.

24. Swick A, Kimple RJ. Wetting the whistle: neurotropic factor improves salivary function. J Clin Invest. 2014; 124: 3282-4.

25. Shiboski CH, Hodgson TA, Ship JA, et al. Management of salivary hypofunction during and after radiotherapy. Oral Surg Oral Med Oral Pathol Oral Radiol Endod. 2007; 103( Suppl S66 e):1-19.

26. Donlan RM, Costerton JW. Biofilms: survival mechanisms of clinically relevant microorganisms. Clin Microbiol Rev. 2002; 15: 167-93.

27. Ng TB, Wang HX. Pharmacological actions ofCordyceps, a prized folk medicine. Journal of Pharmacy and Pharmacology. 2005; 57: 1509-19.

28. Bhattarai $K R$, Junjappa $R$, Handigund $M$, et al. The imprint of salivary secretion in autoimmune disorders and related pathological conditions. Autoimmun Rev. 2018; 17: 376-90

29. Mejía-Benítez MA, Bonnefond A, Yengo L, et al. Beneficial effect of a high number of copies of salivary amylase AMY1 gene on obesity risk in Mexican children. Diabetologia. 2015; 58: 290-4.

30. Santos JL, Saus E, Smalley SV, et al. Copy number polymorphism of the salivary amylase gene: implications in human nutrition research. J Nutrigenet Nutrigenomics. 2012; 5: 117-31. 
31. Yang ZM, Lin J, Chen LH, et al. The roles of AMY1 copies and protein expression in human salivary alpha-amylase activity. Physiol Behav. 2015; 138 : 173-8.

32. Matsuzaki T, Susa T, Shimizu K, et al. Function of the membrane water channel aquaporin-5 in the salivary gland. Acta Histochem Cytochem. 2012; 45: 251-9.

33. Ishikawa Y, Cho G, Yuan Z, et al. Aquaporin-5 water channel in lipid rafts of rat parotid glands. Biochim Biophys Acta. 2006; 1758: 1053-60.

34. Delporte C, Steinfeld S. Distribution and roles of aquaporins in salivary glands. Biochim Biophys Acta. 2006; 1758: 1061-70.

35. Ma T, Song Y, Gillespie A, et al. Defective secretion of saliva in transgenic mice lacking aquaporin-5 water channels. J Biol Chem. 1999; 274: 20071-4.

36. Bhattarai KR, Kim HR, Jung CH. MON-LB289: High Expression of Aquaporin 5 Leads to Increase in Salivary Amylase Level. A Study of Ixeris Dentata in Diabetes Induced Xerostomia Model. Clinical Nutrition. 2016; 35: S260.

37. Evans RL, Bell SM, Schultheis PJ, et al. Targeted disruption of the Nhe1 gene prevents muscarinic agonist-induced up-regulation of $\mathrm{Na}(+) / \mathrm{H}(+)$ exchange in mouse parotid acinar cells. J Biol Chem. 1999; 274: 29025-30.

38. Han L, Wang L, Zhang F, et al. Effect of Phenylephrine Pretreatment on the Expressions of Aquaporin 5 and c-Jun N-Terminal Kinase in Irradiated Submandibular Gland. Radiat Res. 2015; 183: 693-700.

39. Gilbert HF. Protein disulfide isomerase and assisted protein folding. J Biol Chem. 1997; 272: 29399-402.

40. Balaban RS, Nemoto S, Finkel T. Mitochondria, oxidants, and aging. Cell. 2005; 120: 483-95.

41. Inoue $\mathrm{H}$, Kishimoto A, Ushikoshi-Nakayama R, et al. Resveratrol improves salivary dysfunction in a non-obese diabetic (NOD) mouse model of Sjögren's syndrome. J Clin Biochem Nutr. 2016: 16-31.

42. Hafizah AH, Zaiton Z, Zulkhairi A, et al. Piper sarmentosum as an antioxidant on oxidative stress in human umbilical vein endothelial cells induced by hydrogen peroxide. J Zhejiang Univ-Sc B. 2010; 11: 357-65.

43. Chew W, Mathison B, Kimble L, et al. Astaxanthin decreases inflammatory biomarkers associated with cardiovascular disease in human umbilical vein endothelial cells. Faseb J. 2013; 27: 1-17.

44. Jin ML, Park SY, Kim YH, et al. The neuroprotective effects of cordycepin inhibit glutamate-induced oxidative and ER stress-associated apoptosis in hippocampal HT22 cells. Neurotoxicology. 2014; 41: 102-11.

45. Younus $\mathrm{H}$. Therapeutic potentials of superoxide dismutase. Int J Health Sci (Qassim). 2018; 12: 88-93.

46. Ighodaro OM, Akinloye OA. First line defence antioxidants-superoxide dismutase (SOD), catalase (CAT) and glutathione peroxidase (GPX): Their fundamental role in the entire antioxidant defence grid. Alexandria Journal of Medicine. 2018; 54: 287-93.

47. Pedersen AM, Bardow A, Jensen SB, et al. Saliva and gastrointestinal functions of taste, mastication, swallowing and digestion. Oral Dis. 2002; 8: 117-29.

48. Catalán MA, Nakamoto T, \& Melvin JE. The salivary gland fluid secretion mechanisms. The Journal of Medical Investigation. 2009; 56: 192-6.

49. de Almeida PDV, Gregio AM, Machado MA, et al. Saliva composition and functions: a comprehensive review. J Contemp Dent Pract. 2008; 9: 72-80.

50. Kang N, Lee HH, Park I, et al. Development of High Cordycepin-Producing Cordyceps militaris Strains. Mycobiology. 2017; 45: 31-8.

51. Tsai YJ, Lin LC, Tsai TH. Pharmacokinetics of Adenosine and Cordycepin, a Bioactive Constituent ofCordyceps sinensisin Rat. J Agric Food Chem. 2010; 58: 4638-43.

52. Lu H, Li X, Zhang J, et al. Effects of cordycepin on HepG2 and EA.hy926 cells: Potential antiproliferative, antimetastatic and anti-angiogenic effects on hepatocellular carcinoma. Oncol Lett. 2014; 7: 1556-62.

53. Farthing D, Sica D, Gehr T, et al. An HPLC method for determination of inosine and hypoxanthine in human plasma from healthy volunteers and patients presenting with potential acute cardiac ischemia. J Chromatogr B Analyt Technol Biomed Life Sci. 2007; 854: 158-64.

54. Adamson RH, Zaharevitz DW, Johns DG. Enhancement of the Biological Activity of Adenosine Analogs by the Adenosine Deaminase Inhibitor 2'-Deoxycoformycin. Pharmacology. 1977; 15: 84-9.

55. Okabayashi K, Narita T, Takahashi $\mathrm{Y}$, et al. Effect of oxidative stress on secretory function in salivary gland cells. Oxidative Stress-Environmental Induction and Dietary Antioxidants. 2012: 189-200.

56. Matsuzaki T, Susa T, Shimizu K, Sawai N, Suzuki T, Aoki T, Takata K. Function of the membrane water channel aquaporin- 5 in the salivary gland. Acta histochemica et cytochemica. 2012; 45: 251-9.

57. Delporte C, Bryla A, Perret J. Aquaporins in Salivary Glands: From Basic Research to Clinical Applications. Int J Mol Sci. 2016; 17: 166.

58. Mandel AL, Peyrot des Gachons C, Plank KL, et al. Individual differences in AMY1 gene copy number, salivary alpha-amylase levels, and the perception of oral starch. PLoS One. 2010; 5: e13352.

59. Tanaka J, Mishima K. In vitro three-dimensional culture systems of salivary glands. Pathol Int. 2020; 4: 12947. 